\title{
Pregnancy Outcomes in Association with STDs including genital HSV-2 shedding in a South African Cohort Study
}

\author{
Dhayendre Moodley, ${ }^{1}$ Benn Sartorius, ${ }^{2}$ Savithree Madurai, ${ }^{3}$ Vani Chetty, ${ }^{1}$ \\ Suzanne Maman ${ }^{4}$
}

'Department of Obstetrics and Gynaecology, University of KwaZulu-Natal, Durban, South Africa

${ }^{2}$ Discipline of Public Health Medicine, School of Nursing and Public Health, College of Health Sciences, University of KwaZuluNatal, Durban, South Africa ${ }^{3} \mathrm{G}$ lobal Clinical Virology Laboratory, Durban, South Africa ${ }^{4}$ Department of Health Behavior, Gillings School of Global Public Health, University of North Carolina at Chapel Hill, Chapel Hill, North Carolina, USA

Correspondence to Dr Dhayendre Moodley, Department of Obstetrics and Gynaecology, University of KwaZulu-Natal, Durban, South Africa 4013:

moodleyd1@ukzn.ac.za

Received 19 January 2017 Revised 2 March 2017 Accepted 14 March 2017 Published Online First 10 April 2017

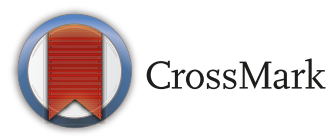

To cite: Moodley $D_{\text {, }}$ Sartorius B, Madurai $S$, et al. Sex Transm Infect 2017:93:460-466.

\section{ABSTRACT}

Objectives Genital herpes simplex virus-2 (HSV-2) shedding in pregnant women in association with neonatal herpes infection has been widely studied but there is limited evidence of its association with

pregnancy outcomes.

Methods In this retrospective observational study, we included a subgroup of pregnant women who were enrolled in a randomized control behavioural intervention study that was conducted in South Africa in 2008-2010. In pregnancy, women had a HIV rapid test done and a genital swab taken to test for curable STIs and HSV-2 DNA. Subsequent visits were scheduled for 6 , 10,14 weeks and 9 months post-delivery. Pregnancy outcomes were documented at the 6-week or 10-week postpartum visit. Women were treated syndromically for curable STIs.

Results Among 615 women included in this data analysis, 36.6\% $(n=225)$ tested HIV positive and 8.3\% $(n=51)$ tested positive for genital HSV-2 shedding during pregnancy. Women $<24$ years and HIV- 1 seropositive women were 1.5 and 2.5 times more likely to test positive for HSV-2 genital shedding respectively. STI treatment records were available for 158/205 (77.1\%) women; all 87 women with symptomatic STIs were treated the same day, and 50/71 (70.4\%) asymptomatic women received treatment at the subsequent visit. Remaining 21 (29.6\%) asymptomatic women did not receive treatment because they failed to return for antenatal follow-up. In a multivariable regression analysis, genital HSV-2 shedding, HIV-1, Neisseria gonorrhoea, Chlamydia trachomatis and Trichomanas vaginalis were not associated with preterm deliveries, still births and low birth weight. However with stratification by treatment for a STI, asymptomatic women who were not treated were 3.3 times more likely to deliver prematurely $(33.3 \% ; n=6 / 18)$ when compared to women who were treated during pregnancy $(13.2 \%$; $n=15 / 114)(p=0.042)$.

Conclusions Genital HSV-2 shedding in pregnancy does not appear to alter pregnancy outcomes. Untreated curable STIs (T.vaginalis, C.trachomatis, N.gonorrhoea) were more likely associated with preterm births.

\section{INTRODUCTION}

Worldwide, women in their reproductive age bear the brunt of the HIV-1 epidemic, and women aged 14-24 years are at particularly high risk. ${ }^{1}$ Younger women are also disproportionately vulnerable to other STIs, unplanned pregnancies and adverse perinatal outcomes. $^{2-4}$ In a secondary analysis of a South African cohort study, the prevalence of Neisseria gonorrhoeae (8.6\%), Trichomonas vaginalis $(17.4 \%)$ and Chlamydia trachomatis (21.9\%) was significantly higher among women $<24$ years. ${ }^{5}$ Young pregnant women in other low-income or middle-income countries are similarly affected by STIs. Using a point-of-care testing strategy in a high-burden low-income setting in Papua New Guinea, women $<24$ years were more than twice (OR 2.38; 95\% CI 1.09 to 5.21 ) likely to test positive for any STI in pregnancy. ${ }^{6}$ Almost half of adolescent pregnant women in a cross-sectional community survey in Tanzania tested positive for at least one STI, and herpes simplex virus-2 (HSV-2) was most commonly detected. ${ }^{7}$ The recent South African antenatal HIV-1 survey also highlighted the high HSV-2 seroprevalence among HIV-1 seropositive pregnant women. ${ }^{8}$

Any or a combination of the above STIs during pregnancy in virtue of its aetiology, pathogenesis and its proximity to the fetal-placental barrier could contribute to unfavourable pregnancy outcomes. Untreated HIV-1 infection, particularly among women who have not sought antenatal care, is significantly associated with stillbirths ( $R R$ 3.3), preterm births (RR 1.5), small for gestational age (RR 1.3) and low birthweight (RR 1.62) babies.' Curable STIs in pregnancy, particularly if undiagnosed and untreated, have also been implicated in adverse pregnancy outcomes. C. trachomatis and $N$. gonorrhoeae in particular are commonly associated with premature rupture of membranes, preterm deliveries, fetal demise and low birth weight. $^{10-13}$ Studies reporting genital shedding of HSV-2 in pregnancy are limited and provide little insight on the impact thereof on pregnancy outcomes. $^{14-17}$

We previously reported on the incidence and prevalence of three curable STIs in relation to HIV-1 in a cohort of pregnant women and remarked on the large proportion of asymptomatic STIs that would go undiagnosed when syndromic management is implemented. ${ }^{5}$ In this current analysis, we report on the prevalence of genital HSV-2 shedding in the same cohort of pregnant women and further explore the effect of genital shedding of HSV-2 and the previously reported STIs in association with treatment on pregnancy outcomes. 


\section{METHODS}

\section{Definitions of pregnancy outcomes}

Births occurring $<37$ weeks gestation were defined as preterm. Gestational age was determined by obstetric measurements and in the absence of an ultrasound done within 24 weeks, an average measure by symphysis fundal height, last menstrual date and palpation was used to estimate gestational age at the first antenatal visit. Low birth weight was defined as $<2500 \mathrm{~g}$ in term deliveries $\geq 37$ weeks gestation and stillbirths were defined as fetal demise $\geq 21$ weeks gestational age. A miscarriage was defined as fetal demise $<21$ weeks.

\section{Study design}

This is a secondary analysis of the South African HIV Antenatal Post-test Support Study (SAHAPS) study cohort, a behavioural intervention randomised control trial, that was conducted at a public health clinic in Umlazi, a periurban residential township in South Africa between May 2008 and June 2010. ${ }^{18}$ Pregnant women registering at the antenatal clinic were enrolled if they were 18 years or older, had not previously tested for HIV-1, were in a sexual relationship for the past 6 months and planned to reside in the area until the end of the study. Women who provided informed consent were interviewed and subsequently randomised to one of two arms to receive enhanced counselling sessions (intervention) or receive the standard counselling session (control). All enrolled participants received the standard prescribed antenatal care, had a genital swab taken to test for STIs and had a HIV-1 rapid test done. Details of the HIV-1 testing procedure are described in the primary manuscript. ${ }^{18}$ While participants continued with antenatal care at subsequent visits, participants who tested HIV-1 negative at the first visit also had a repeat HIV-1 test performed after 34 weeks gestation. Subsequent study visits were scheduled for 6,10,14 weeks and 9 months after delivery. Our retention strategy included a maximum of three telephonic contacts in the event of participants missing their study visits, and a home visit if participants fail to return to the clinic after telephonic reminders. Pregnancy outcomes were documented at the 6 -week or 10 -week postpartum visit. A genital swab was repeated at the 14 -week postpartum visit. Genital swabs taken from pregnant women at their first antenatal visit and postpartum visit were tested for the curable STIs (N. gonorrhoeae, C. trachomatis and T. vaginalis) by PCR in real time and remaining genital specimens were processed and stored at $-70^{\circ} \mathrm{C}$.

In the parent study, a randomised controlled trial, 1480 pregnant women were randomised to an intervention arm or a control arm and expected to return for follow-up visits. Data for 1183 women were analysed at the 14-week postpartum visit. In summary, the counselling intervention had no effect on the incidence of STIs at the 14-week postpartum visit.

In this retrospective observational study, we conducted a subanalysis of data for 615 pregnant women who were enrolled in the parent study and for whom we had adequate volumes of stored crude extracts of DNA from the genital specimens with an overall aim to determine the prevalence of HSV-2 shedding in the genital tract and evaluate the pregnancy outcomes in association with HSV-2 shedding and other STIs detected during pregnancy.

\section{Detection of $N$. gonorrhoeae, C. trachomatis and T. vaginalis}

As described in our previous report, the swabs were processed for the detection of N. gonorrhoeae, C. trachomatis and T. vaginalis using the BD Probetec ET Amplified DNA Assay (Becton Dickinson, Maryland, USA) and Strand Displacement technology. ${ }^{5}$

\section{Detection of $\mathrm{HSV}-1 / 2$}

Crude extracts of DNA remaining after PCR testing for N. gonorrhoeae, C. trachomatis and T. vaginalis were stored at $-70^{\circ} \mathrm{C}$. These DNA extracts were recently tested for HSV-1/2 DNA using the Light Cycler HSV1/2 Detection Kit Light Mix Kit (Roche Diagnostics, USA). The Kit is a real-time PCR assay that has been designed and adapted for use on The Light Cycler Roche Instrument.

\section{Treatment for C. trachomatis, N. gonorrhoeae and T. vaginalis}

In compliance with the local syndromic management protocol, women reporting or presenting with vaginal discharge syndrome suggestive of an STD were initiated on treatment on the same day. The results from the laboratory diagnosis were available between 2 and 3 weeks and women who were asymptomatic but tested positive by laboratory diagnosis were contacted telephonically to inform them of their results and asked to return to the clinic at their earliest convenience or reminded of their next scheduled antenatal visit for initiation of treatment. Study nurses continued to provide antenatal care to all participants until delivery; in this way, participants with asymptomatic STIs would be initiated on treatment at their next routine clinic visit if they had not returned earlier.

\section{Treatment for HIV-1}

Between 2008 and 2010, pregnant women who tested positive for HIV-1 at their first antenatal visit were initiated on Zidovudine prophylaxis from 28 weeks of gestation for prevention of mother-to-child transmission of HIV-1 and subsequently commenced on a triple antiretroviral regimen when their CD4 count was available and met the criteria for treatment (CD4 $<200$ cells $/ \mathrm{mL})$.

\section{Statistical analysis}

Data were analysed using Stata V.13.0 (StataCorp. 2013. Stata Statistical Software: Release V.13. College Station, TX: StataCorp LP). The difference in mean of continuous explanatory variables by adverse birth outcome was assessed using the Student's t-test. If a given explanatory variable were not normal, then the Wilcoxon rank-sum (Mann-Whitney U) test was used instead. The association between adverse birth outcome and categorised explanatory risk factors was assessed using a Pearson $\chi^{2}$ test. If any cell count in the cross tabulation contained fewer than five expected observations, then the Fisher's exact test was used instead. Bivariate and multivariable adjusted logistic regression models were developed to assess the association of explanatory variables for adverse birth outcomes in the presence of other potential confounders/risk factors.

All the multivariable models were built using backwards elimination based on the likelihood ratio test to discriminate between variables that needed to be retained or if they could be removed without significantly altering the model fit. Variables in the final multivariable models were checked for collinearity using variance inflation factors. An adjusted $\mathrm{p}$ value of $<0.05$ was considered statistically significant.

A written informed consent was obtained from all women who participated in the main study. 


\section{RESULTS}

Data for a total number of 615 pregnant women were included in this subanalysis, $36(5.8 \%)$ of whom did not return after delivery and for whom we do not have birth outcomes. The average age of women in this subanalysis was 25.4 years, $49.4 \%$ were in the 18-24-year age group. Two hundred and ninetyfour (47.9\%) achieved only primary education and only $24.7 \%$ were living with their partner. Women in the subcohort had an average number of two pregnancies (36.8\%) and 38.4\% were first-time pregnancies. The median gestational age at antenatal registration was 24 weeks (IQR 20-27).

With a HIV-1 seroprevalence of $36.6 \%, 342$ HIV-1 seronegative women were retested for HIV-1 prior to delivery. There were five HIV-1 seroconversions over a cumulative period of 157.37 years, HIV-1 incidence in pregnancy being 3.18 per 100 woman-years (95\% CI 1.0 to 7.4). Four of the five women were in the 18-24-year age group.

One-third of pregnant women in this substudy cohort $(33.4 \%$; 95\% CI 29.7 to 37.3 ) tested positive for any STIs and C. trachomatis and T. vaginalis were the most common pathogens; $17.8 \%$ and $15.3 \%$, respectively. $N$. gonorrhoeae was detected in $6.4 \%$ (95\% CI 4.6 to 8.7$)$ of the women. Fifty-one (8.30\%) women presented with more than one STI. Among the 203 women with any STI, only $87(42.9 \%)$ women were symptomatic at the time of testing and at an average gestational age of 24 weeks. More than half $(n=11657.1 \%)$ were asymptomatic and did not receive treatment on the same day. The average gestational age at which these women tested positive for an STI was 24 weeks and the next clinic visit was scheduled for 32 weeks. Treatment records were available for $158(77.8 \%)$ women with any STI, all 87 women with symptomatic STIs were treated the same day and 50 (70.4\%) among 71 asymptomatic women received treatment at the subsequent antenatal visit. Twenty-one (29.6\%) of the asymptomatic women with an STI did not receive treatment. Reasons for women not receiving treatment were referrals to a regional hospital or women did not return for antenatal visits.

Genital HSV-2 shedding was prevalent in 51 of $615(8.3 \%$; $95 \%$ CI 6.3 to 10.8 ) women at the first antenatal visit. In a multivariable analysis adjusted for socioeconomic status, gravidity, C. trachomatis, T. vaginalis and N. gonorrhoeae, HIV-1 positive women were 2.5 times more likely to test positive for HSV-2 shedding (OR 2.5; 95\% CI 1.44 to 4.35 ) (table 1). HSV-2 shedding was also significantly more common among 18-24-year age group $(p=0.021)$. Only one of the five $(20 \%)$ incident cases of HIV-1 was positive for genital HSV-2 shedding. Of the women who tested positive for HSV-2 genital shedding, six $(11.8 \%)$ reported genital ulcers once before and $27.5 \%$ reported an abnormal vaginal discharge in the past year.

Only $20(39.2 \%)$ women who tested positive for HSV-2 shedding at antenatal registration were symptomatic at the time of genital shedding. History of genital ulcers was not significantly associated with HSV-2 genital shedding $(p=0.24)$. The median gestational age at which women tested positive for genital HSV-2 shedding was 25.3 weeks (IQR 193.28.7).

The pregnancy outcomes for 579 women were well documented; there were 542 live births with a median birth weight of $3.2 \mathrm{~kg}$ (IQR 2.9-3.5) and $47(8.64 \%$; 95\% CI 6.5 to 11.4$)$ were of low birth weight $(<2500 \mathrm{~g})$. One hundred $(18.15 \%$; $95 \% \mathrm{CI}$

Table 1 Determinants of HSV-2 shedding in genital tract of pregnant women in South Africa, $2010(n=615)$

\begin{tabular}{|c|c|c|c|c|c|}
\hline \multirow[b]{2}{*}{ Variable } & \multicolumn{2}{|l|}{ HSV-2 (baseline) } & \multirow{2}{*}{$\begin{array}{l}\text { Unadjusted } \\
\text { p Value }\end{array}$} & \multicolumn{2}{|c|}{ Multivariable adjusted* } \\
\hline & Negative $(n=552)$ & Positive $(n=63)$ & & OR $(95 \% \mathrm{CI})$ & p Value \\
\hline \multicolumn{6}{|l|}{ Age group: n (row \%) } \\
\hline $18-24$ & $293(88.0)$ & $40(12.0)$ & 0.28 & 1 (ref.) & \\
\hline $25-34$ & $219(91.6)$ & $20(8.4)$ & & $0.47(0.25$ to 0.91$)$ & 0.02 \\
\hline $35+$ & $40(93.0)$ & $3(7.0)$ & & 0.29 (0.07 to 1.24$)$ & 0.09 \\
\hline \multicolumn{6}{|c|}{ Socioeconomic status: $\mathrm{n}$ (row \%) } \\
\hline Low & $196(87.5)$ & $28(12.5)$ & 0.34 & 1 (ref.) & \\
\hline Medium & $235(92.2)$ & $20(7.8)$ & & $0.63(0.36$ to 1.12$)$ & 0.12 \\
\hline High & $107(88.4)$ & $14(11.6)$ & & 0.98 (0.48 to 1.98$)$ & 0.95 \\
\hline Unknown & $14(93.3)$ & $1(6.7)$ & & 0.48 (0.06 to 3.99$)$ & 0.50 \\
\hline \multicolumn{6}{|l|}{ HIV-1: n (row \%) } \\
\hline Negative & $357(92.7)$ & $28(7.3)$ & 0.00 & 1 (ref.) & \\
\hline Positive & $195(84.8)$ & $35(15.2)$ & & 2.46 (1.43 to 4.21$)$ & 0.00 \\
\hline \multicolumn{6}{|c|}{ Neisseria gonorrhoeae, n (row \%) } \\
\hline Negative & $511(89.8)$ & $58(10.2)$ & 0.60 & 1 (ref.) & \\
\hline Positive & $34(87.2)$ & $5(12.8)$ & & 1.02 (0.37 to 2.81$)$ & 0.97 \\
\hline \multicolumn{6}{|c|}{ Trichomonas vaginalis, $\mathrm{n}$ (row \%) } \\
\hline Negative & $464(89.7)$ & $53(10.3)$ & 0.83 & 1 (ref.) & \\
\hline Positive & $81(89.0)$ & $10(11.0)$ & & $0.93(0.44$ to 1.96$)$ & 0.85 \\
\hline \multicolumn{6}{|c|}{ Chlamydia trachomatis, n (row \%) } \\
\hline Negative & $443(89.7)$ & $51(10.3)$ & 0.97 & 1 (ref.) & \\
\hline Positive & $103(89.6)$ & $12(10.4)$ & & 0.92 (0.46 to 1.84$)$ & 0.81 \\
\hline Gravidity: median (IQR) & $2(1-2)$ & $2(1-3)$ & 0.62 & $1.26(0.95$ to 1.66$)$ & 0.11 \\
\hline \multicolumn{6}{|l|}{ Clinical: n (\%) } \\
\hline Asymptomatic & $363(90.3)$ & $39(9.7)$ & 0.53 & 1 (ref.) & \\
\hline Symptomatic & $188(88.7)$ & $24(11.3)$ & & $0.99(0.57$ to 1.74$)$ & 0.98 \\
\hline
\end{tabular}


15.1 to 21.7 ) women delivered preterm (<37 weeks). Ten women $(1.7 \%$; 95\% CI 0.9 to 3.3$)$ aborted spontaneously (<21 weeks) and $13(2.25 \%$; 95\% CI 1.3 to 3.9) pregnancies ended in stillbirths $\geq 21$ weeks of gestation. There were 14 (2.4\%; $95 \%$ CI 1.4 to 4.1$)$ neonatal deaths.

The stillbirth rates were higher but not significantly higher among HSV-2 shedders (17.5\% vs 12\%), 18-24-year-old women $(13.8 \%$ vs $10.9 \%)$, HIV-1 positive women $(14.8 \%$ vs $11.2 \%)$, women positive for N. gonorrheae (23.1\% vs $12 \%)$ and positive for $T$. vaginalis $(17.6 \%$ vs $11.6 \%)$. In an unadjusted analysis, women infected with $N$. gonorrhoeae were 2.2 times more likely to have had their pregnancy ending in a stillbirth $(\mathrm{p}<0.05)$ and this association was marginally significant in a multivariable logistic regression model using backwards elimination of variables in the model (table 2).

Genital HSV-2 shedding, HIV-1, N. gonorrhoeae, C. trachomatis and T. vaginalis were also not associated with increased risk for preterm deliveries (table 3) and low birth weight (table 4). However, asymptomatic women with untreated curable STIs were 3.3 times more likely to deliver prematurely $(p=0.048)$ when compared with women who received treatment during pregnancy (table 4). A comparison of pregnancy outcomes among women who received syndromic treatment on the day of diagnosis and women who initiated treatment at the subsequent antenatal visit yielded no difference in the proportion of stillbirths, preterm deliveries and low birthweight babies.

The proportion of live births was not significantly lower among women with multiple STIs (95.74\%) when compared with women with no STIs (94.21\%) and women with a single STI $(91.67 \%) \quad(p=0.308)$. Likewise, the proportion of low birth weight (LBW) and preterm birth (PTB) babies born to women with coinfections $(6.67 \%, 18.18 \%)$ were not significantly higher than women with a single STI $(8.50 \%, 17.42 \%)$ and no STI $(8.99 \%, 18.23 \%)(\mathrm{p}=0.476, \mathrm{p}=0.486)$.

\section{DISCUSSION}

In this secondary analysis of a cohort study of young women in a periurban community with an antenatal HIV-1 seroprevalence of $36.6 \%$, we report genital HSV-2 shedding in $8.3 \%$ of the women during pregnancy. HIV-1 positive pregnant women in our study were twice more likely to be diagnosed with genital HSV-2 shedding. HSV-2 shedding in pregnancy, after adjusting for HIV-1, T. vaginalis, C. trachomatis or $\mathrm{N}$. gonorrhoeae, and demographic characteristics were not associated with the occurrence of stillbirths, preterm births and low birthweight babies. However, untreated curable STIs are more likely associated with preterm births.

Table 2 HSV-2 shedding and modifiers that influence live births in South Africa, $2010(n=615)$

\begin{tabular}{|c|c|c|c|c|c|c|}
\hline \multirow[b]{2}{*}{ Variable } & \multicolumn{2}{|l|}{ Birth outcome } & \multirow{2}{*}{$\begin{array}{l}\text { Unadjusted } \\
\text { OR }(95 \% \mathrm{CI}) \\
\text { for adverse outcome }\end{array}$} & \multirow[b]{2}{*}{$\mathrm{p}$ Value } & \multicolumn{2}{|l|}{ Multivariable adjusted* } \\
\hline & $\begin{array}{l}\text { Live born } \\
(\mathrm{N}=538,87.5 \%)\end{array}$ & $\begin{array}{l}\text { Not live born } \\
(\mathrm{N}=77,12.5 \%)\end{array}$ & & & $\begin{array}{l}\text { OR }(95 \% \mathrm{Cl}) \\
\text { for adverse outcome }\end{array}$ & p Value \\
\hline \multicolumn{7}{|l|}{ HSV-2 shedding: $n(\%)$} \\
\hline No & $486(88)$ & $66(12)$ & 1 (ref.) & & 1 (ref.) & \\
\hline Yes & $52(82.5)$ & $11(17.5)$ & $1.6(0.8$ to 3.1$)$ & 0.21 & $1.3(0.7$ to 2.8$)$ & 0.42 \\
\hline \multicolumn{7}{|l|}{ Age group: n (\%) } \\
\hline $18-24$ & $287(86.2)$ & $46(13.8)$ & 1 (ref.) & & 1 (ref.) & \\
\hline $25-34$ & $213(89.1)$ & $26(10.9)$ & $0.8(0.5$ to 1.3$)$ & 0.30 & $0.6(0.3$ to 1.1$)$ & 0.12 \\
\hline $35-44$ & $38(88.4)$ & $5(11.6)$ & $0.8(0.3$ to 2.2$)$ & 0.69 & $0.5(0.1$ to 1.6$)$ & 0.22 \\
\hline \multicolumn{7}{|l|}{ HIV-1: n (\%) } \\
\hline No & $342(88.8)$ & $43(11.2)$ & 1 (ref.) & & 1 (ref.) & \\
\hline Yes & $196(85.2)$ & $34(14.8)$ & $1.4(0.9$ to 2.2$)$ & 0.19 & 1.3 (0.8 to 2.1$)$ & 0.39 \\
\hline Gravidity: median (IQR) & $2(1-2)$ & $2(1-3)$ & $1.1(0.9$ to 1.3$)$ & 0.55 & $1.2(0.9$ to 1.6$)$ & 0.14 \\
\hline \multicolumn{7}{|c|}{ Socioeconomic status: $\mathrm{n}(\%)$} \\
\hline Unknown & $13(86.7)$ & $2(13.3)$ & $0.9(0.2$ to 4.1$)$ & 0.88 & 0.9 (0.2 to 4.5$)$ & 0.92 \\
\hline Low & $191(85.3)$ & $33(14.7)$ & 1 (ref.) & & 1 (ref.) & \\
\hline Medium & $229(89.8)$ & $26(10.2)$ & 0.7 (0.4 to 1.1$)$ & 0.13 & 0.7 (0.4 to 1.3$)$ & 0.26 \\
\hline High & $105(86.8)$ & $16(13.2)$ & $0.9(0.5$ to 1.7$)$ & 0.70 & $1(0.5$ to 1.9$)$ & 0.99 \\
\hline \multicolumn{7}{|c|}{ Neisseria gonorrhoeae, $\mathrm{n}(\%) \dagger$} \\
\hline No & $501(88.0)$ & $68(12.0)$ & 1 (ref.) & & 1 (ref.) & \\
\hline Yes & $30(76.9)$ & $9(23.1)$ & $2.2(1$ to 4.9$)$ & 0.05 & $2.2(1.0$ to 4.9$)$ & 0.05 \\
\hline \multicolumn{7}{|c|}{ Trichomonas vaginalis, $\mathrm{n}(\%) \dagger$} \\
\hline No & $457(88.4)$ & $60(11.6)$ & 1 (ref.) & & 1 (ref.) & \\
\hline Yes & $75(82.4)$ & $16(17.6)$ & $1.6(0.9$ to 3$)$ & 0.12 & $1.6(0.9$ to 3$)$ & 0.13 \\
\hline \multicolumn{7}{|c|}{ Chlamydia trachomatis, n $(\%) \ddagger$} \\
\hline No & $429(86.8)$ & 65 (13.2) & 1 (ref.) & & 1 (ref.) & \\
\hline Yes & $103(89.6)$ & $12(10.4)$ & $0.8(0.4$ to 1.5$)$ & 0.43 & 0.7 (0.4 to 1.4$)$ & 0.28 \\
\hline \multicolumn{7}{|l|}{ Treated for STls } \\
\hline No & $17(94.5)$ & $1(5.5)$ & 1 (ref.) & & & \\
\hline Yes & $108(93.9)$ & $7(6.1)$ & $0.91(0.11$ to 7.74$)$ & 0.69 & - & - \\
\hline Same day & $36(94.7)$ & $2(5.3)$ & 1 (ref.) & & & \\
\hline Subsequent visit & $72(93.5)$ & $5(6.5)$ & $1.25(0.23$ to 6.76$)$ & 0.58 & & \\
\hline
\end{tabular}


Table 3 HSV-2 shedding and modifiers that may influence preterm deliveries in South Africa, $2010(n=574)^{*}$

\begin{tabular}{|c|c|c|c|c|c|c|}
\hline \multirow[b]{2}{*}{ Variable } & \multicolumn{2}{|l|}{ Birth outcome } & \multirow[b]{2}{*}{$\begin{array}{l}\text { OR }(95 \% \mathrm{Cl}) \\
\text { for adverse outcome }\end{array}$} & \multirow[b]{2}{*}{$p$ Value } & \multicolumn{2}{|l|}{ Multivariable adjustedt } \\
\hline & $\begin{array}{l}\text { Term } \\
(\mathrm{N}=415,72.3 \%)\end{array}$ & $\begin{array}{l}\text { Preterm } \\
(\mathrm{N}=159,27.7 \%)\end{array}$ & & & $\begin{array}{l}\text { OR }(95 \% \mathrm{Cl}) \\
\text { for adverse outcome }\end{array}$ & p Value \\
\hline \multicolumn{7}{|l|}{ HSV-2 shedding: $n(\%)$} \\
\hline No & $372(72.1)$ & $144(27.9)$ & 1 (ref.) & & 1 (ref.) & \\
\hline Yes & $43(74.1)$ & $15(25.9)$ & $0.9(0.5$ to 1.7$)$ & 0.74 & $0.9(0.5$ to 1.7$)$ & 0.68 \\
\hline \multicolumn{7}{|l|}{ Age group: $\mathrm{n}(\%)$} \\
\hline $18-24$ & $216(70.8)$ & $89(29.2)$ & 1 (ref.) & & 1 (ref.) & \\
\hline $25-34$ & $162(71.7)$ & $64(28.3)$ & 1 (0.7 to 1.4$)$ & 0.83 & $0.9(0.6$ to 1.3$)$ & 0.64 \\
\hline $35-44$ & $37(86.0)$ & $6(14.0)$ & $0.4(0.2$ to 1$)$ & 0.04 & $0.4(0.2$ to 0.9$)$ & 0.04 \\
\hline \multicolumn{7}{|l|}{ HIV-1: n (\%) } \\
\hline No & $263(73.1)$ & $97(26.9)$ & 1 (ref.) & & 1 (ref.) & \\
\hline Yes & $152(71.0)$ & $62(29.0)$ & $1.1(0.8$ to 1.6$)$ & 0.6 & $1.1(0.7$ to 1.6$)$ & 0.69 \\
\hline Gravidity: median (IQR) & $2(1-2)$ & $2(1-2)$ & $0.9(0.8$ to 1.1$)$ & 0.34 & 1 (0.8 to 1.2$)$ & 0.93 \\
\hline \multicolumn{7}{|c|}{ Socioeconomic status: $\mathrm{n}(\%)$} \\
\hline Unknown & $11(78.6)$ & $3(21.4)$ & $0.9(0.2$ to 4.1$)$ & 0.88 & $0.8(0.2$ to 3.2$)$ & 0.76 \\
\hline Low & $150(73.2)$ & $55(26.8)$ & 1 (ref.) & & 1 (ref.) & \\
\hline Medium & $166(68.3)$ & $77(31.7)$ & $0.7(0.4$ to 1.1$)$ & 0.13 & $1.3(0.8$ to 1.9$)$ & 0.27 \\
\hline High & $88(78.6)$ & $24(21.4)$ & $0.9(0.5$ to 1.7$)$ & 0.70 & $0.7(0.4$ to 1.3$)$ & 0.31 \\
\hline \multicolumn{7}{|c|}{ Neisseria gonorrhoeae, $\mathrm{n}(\%) \ddagger$} \\
\hline No & $390(73.0)$ & $144(27.0)$ & 1 (ref.) & & 1 (ref.) & \\
\hline Yes & $21(61.8)$ & $13(38.2)$ & $1.7(0.8$ to 3.4$)$ & 0.16 & 1.7 (0.8 to 3.5$)$ & 0.17 \\
\hline \multicolumn{7}{|c|}{ Trichomonas vaginalis.n (\%)§ } \\
\hline No & $354(72.7)$ & $133(27.3)$ & 1 (ref.) & & 1 (ref.) & \\
\hline Yes & $58(70.7)$ & $24(29.3)$ & $1.1(0.7$ to 1.8$)$ & 0.71 & $1.1(0.7$ to 1.9$)$ & 0.67 \\
\hline \multicolumn{7}{|c|}{ Chlamydia trachomatis, n (\%)§ } \\
\hline No & $334(72)$ & $130(28)$ & 1 (ref.) & & 1 (ref.) & \\
\hline Yes & $78(74.3)$ & $27(25.7)$ & $0.9(0.5$ to 1.4$)$ & 0.63 & $0.8(0.5$ to 1.2$)$ & 0.27 \\
\hline \multicolumn{7}{|l|}{ Treated for STIs } \\
\hline No & $12(66.7)$ & $6(33.3)$ & 1 (ref.) & & & \\
\hline Yes & $99(86.8)$ & $15(13.2)$ & 3.3 (1.08 to 10.12$)$ & $0.041 t$ & - & - \\
\hline Same day & $68(88.3)$ & $9(11.7)$ & 1 (ref.) & & & \\
\hline Subsequent visit & $31(83.8)$ & $6(16.2)$ & $1.46(0.48$ to 4.47$)$ & 0.346 & & \\
\hline
\end{tabular}

The South African antenatal survey in 2012 underscored the high HSV-2 seroprevalence in the antenatal population and particularly the strong correlation between HIV-1 and HSV-2 seroprevalence. 8 Similar to the findings of the antenatal survey, HIV-1 positive pregnant women in our study were twice more likely to be diagnosed with HSV-2 shedding. However, unlike HSV-2 seroprevalence which is known to increase with age, genital HSV-2 shedding was significantly more common among the younger women in our study. Studies have reported higher HSV-2 incidence among younger women (18-24 years), and increased genital shedding is characteristically related to incident HSV-2 infections. The absence of serological testing in our study is a major limitation to confirming whether the younger women presented with incident HSV-2 infections.

Our finding of genital shedding in $15 \%$ of HIV-1 positive women in pregnancy has implications for preventing a recurrence in shedding around the time of labour. In recent studies of South African women in labour, genital shedding of HSV-2 was significantly more common among HIV-1 positive women (17.2-30.8\%) versus HIV-1 negative women (9.5-11.8\%) and more than $90 \%$ of these women were asymptomatic. ${ }^{16} 17$ The authors concluded that reactivation of HSV-2 is more likely to occur among HIV-1 positive women in labour and certainly has implications for screening and treatment of neonatal herpes. In a Cochrane systematic review, Holier and Wendel concluded that antiviral prophylaxis for HSV-2 in women in pregnancy reduces the risk of a recurrence in genital shedding and the risk of neonatal infection. ${ }^{19}$ Further studies are needed to determine the cost-effectiveness of treating all HSV-2 seropositive pregnant women or targeted treatment of HIV-1/HSV-2 coinfected pregnant women.

Our findings of similar pregnancy outcomes among HIV-1 infected and uninfected women are not surprising since all HIV-1 positive pregnant women in this randomised control study received antiretroviral prophylaxis for prevention of mother to child transmission (PMTCT) or subsequently initiated antiretroviral treatment if eligible. In a multivariable regression analysis adjusting for demographic characteristics and antiretroviral use in pregnant women from the same catchment population as our study, HIV-1 infection in the absence of antiretroviral treatment remained strongly associated with an increased odds of preterm delivery, stillbirths, low birth weight 
Table 4 HSV-2 shedding and modifiers that may influence birth weight in South Africa, $2010(n=557)^{*}$

\begin{tabular}{|c|c|c|c|c|c|c|}
\hline \multirow[b]{2}{*}{ Variable } & \multicolumn{2}{|l|}{ Birth outcome } & \multirow[b]{2}{*}{$\begin{array}{l}\text { OR }(95 \% \mathrm{Cl}) \\
\text { for adverse outcome }\end{array}$} & \multirow[b]{2}{*}{ p Value } & \multicolumn{2}{|l|}{ Multivariable adjustedt } \\
\hline & $\begin{array}{l}\text { Normal birth } \\
\text { weight }(\mathrm{N}=502,90.1 \%)\end{array}$ & $\begin{array}{l}\text { Low birth } \\
\text { weight }(\mathrm{N}=55,9.9 \%)\end{array}$ & & & $\begin{array}{l}\text { OR }(95 \% \mathrm{Cl}) \\
\text { for adverse outcome }\end{array}$ & p Value \\
\hline \multicolumn{7}{|l|}{ HSV-2 shedding: $n(\%)$} \\
\hline No & $454(90.6)$ & $47(9.4)$ & 1 (ref.) & & 1 (ref.) & \\
\hline Yes & $48(85.7)$ & $8(14.3)$ & $1.6(0.7$ to 3.6$)$ & 0.25 & $1.4(0.6$ to 3.2$)$ & 0.46 \\
\hline \multicolumn{7}{|l|}{ Age group: $\mathrm{n}(\%)$} \\
\hline $18-24$ & $269(90.3)$ & $29(9.7)$ & 1 (ref.) & & 1 (ref.) & \\
\hline $25-34$ & $196(89.5)$ & $23(10.5)$ & $1.1(0.6$ to 1.9$)$ & 0.77 & $1.1(0.5$ to 2.1$)$ & 0.87 \\
\hline $35-44$ & $37(92.5)$ & $3(7.5)$ & $0.8(0.2$ to 2.6$)$ & 0.65 & $0.8(0.2$ to 3.3$)$ & 0.75 \\
\hline \multicolumn{7}{|l|}{ HIV-1: $n(\%)$} \\
\hline No & $328(91.9)$ & $29(8.1)$ & 1 (ref.) & & 1 (ref.) & \\
\hline Yes & $174(87.0)$ & $26(13.0)$ & 1.7 (1 to 3$)$ & 0.07 & $1.7(0.9$ to 3.1$)$ & 0.05 \\
\hline Gravidity: median (IQR) & $2(1-2)$ & $2(1-2)$ & $0.9(0.7$ to 1.2$)$ & 0.47 & $0.9(0.6$ to 1.2$)$ & 0.44 \\
\hline \multicolumn{7}{|c|}{ Socioeconomic status: $\mathrm{n}(\%)$} \\
\hline Unknown & $13(92.9)$ & $1(7.1)$ & $0.5(0.1$ to 4.1$)$ & 0.53 & $0.6(0.1$ to 5$)$ & 0.63 \\
\hline Low & $168(87.0)$ & $25(13.0)$ & 1 (ref.) & & 1 (ref.) & \\
\hline Medium & $218(91.2)$ & $21(8.8)$ & $0.6(0.4$ to 1.2$)$ & 0.17 & $0.7(0.4$ to 1.2$)$ & 0.19 \\
\hline High & $103(92.8)$ & $8(7.2)$ & $0.5(0.2$ to 1.2$)$ & 0.13 & $0.5(0.2$ to 1.1$)$ & 0.09 \\
\hline \multicolumn{7}{|c|}{ Neisseria. gonorrhoeae, n (\%)‡ } \\
\hline No & $467(90.2)$ & $51(9.8)$ & 1 (ref.) & & 1 (ref.) & \\
\hline Yes & $29(90.6)$ & $3(9.4)$ & $0.9(0.3$ to 3.2$)$ & 0.93 & $0.9(0.2$ to 3.1$)$ & 0.84 \\
\hline \multicolumn{7}{|c|}{ Trichomonas vaginalis, $\mathrm{n}(\%) \S$} \\
\hline No & $428(90.7)$ & $44(9.3)$ & 1 (ref.) & & 1 (ref.) & \\
\hline Yes & $69(87.3)$ & $10(12.7)$ & $1.4(0.7$ to 2.9$)$ & 0.36 & $1.3(0.6$ to 2.8$)$ & 0.49 \\
\hline \multicolumn{7}{|c|}{ Chlamydia trachomatis, n (\%)§ } \\
\hline No & $398(89.6)$ & $46(10.4)$ & 1 (ref.) & & 1 (ref.) & \\
\hline Yes & $99(92.5)$ & $8(7.5)$ & $0.7(0.3$ to 1.5$)$ & 0.37 & $0.6(0.3$ to 1.4$)$ & 0.27 \\
\hline \multicolumn{7}{|l|}{ Treated for STIs } \\
\hline No & $17(94.5)$ & $1(5.5)$ & 1 (ref.) & & & \\
\hline Yes & $106(93.8)$ & $7(6.2)$ & $0.89(0.10$ to 7.70$)$ & 0.698 & - & - \\
\hline Same day & $72(94.5)$ & $5(6.5)$ & 1 (ref.) & & & \\
\hline Subsequent visit & $34(94.4)$ & $2(5.6)$ & 0.85 (0.11 to 4.53$)$ & 0.606 & & \\
\hline
\end{tabular}

and small for gestational age. ${ }^{9}$ A recent meta-analysis of 35 studies showed consistent evidence of a strong association between maternal HIV-1 infection and preterm birth, low birth weight, miscarriages and stillbirths, largely in Sub-Saharan Africa. $^{20}$ The Lancet HIV meta-analysis underscored the implications of not providing antiretroviral treatment to pregnant women. ${ }^{20}$

All STIs in pregnancy by virtue of their close proximity to the placenta are plausible causes of premature rupture of membranes, preterm deliveries, fetal demise and low birth weight. Our findings of the lack of association between the curable STIs and adverse pregnancy outcomes are also supported by many other studies that demonstrated an improvement in pregnancy outcomes when early screening and treatment of STIs are included in the antenatal care package. The authors in these studies concluded that screening and treatment of C. trachomatis in the first trimester resulted in significantly lower rates of preterm births, particularly among adolescents, when compared with the reference group of women who had C. trachomatis detected later in pregnancy. ${ }^{21}$ Earlier studies in Uganda and India also found a reduction in low birth weight, preterm delivery, stillbirths and neonatal deaths in women with recognised and treated STIs. ${ }^{22} 23$ The higher preterm birth rate among the asymptomatic women in our study who did not return for follow-up and therefore not receive treatment is additional evidence that STIs can cause adverse pregnancy outcomes if untreated.

It must be noted that pregnant women in our study who presented with a symptomatic genital tract infection received syndromic management on the same day, while women who were asymptomatic but had a laboratory diagnosis of any of the curable STIs also received appropriate treatment at their subsequent antenatal visit but before delivery. With the use of laboratory investigations in this randomised controlled behavioural intervention study, we were able to provide maximum treatment coverage for women with $N$. gonorrhoeae, C. trachomatis or $T$. vaginalis who were symptomatic or asymptomatic. Although, besides being costly and laboratory based, treatment is delayed until the next visit and there is no guarantee that all women will return for subsequent antenatal visits. Our findings have implications for re-examining antenatal care guidelines that only prescribe syndromic management in the detection and treatment of STIs. More recent studies evaluating point-of-care tests for early detection of STIs and exploring the acceptability and feasibility 
of on-site testing strategies for pregnant women are encouraging. ${ }^{64-26}$ Early detection and treatment of curable STIs have an impact on pregnancy outcomes and could avert incident HIV-1 infections during pregnancy. ${ }^{27}$

Our study has several limitations. The primary study excluded women who registered late for antenatal care and are therefore excluded from our analysis. Our findings are therefore only relevant to women who seek antenatal care before 34 weeks in pregnancy. Other curable STIs that could have also contributed to adverse pregnancy outcomes such as syphilis and bacterial vaginosis were omitted in the data collection. We did not include these tests in the primary study, although women were routinely screened for syphilis.

In conclusion, genital HSV-2 shedding in pregnancy does not appear to alter pregnancy outcomes; however, untreated curable STIs (T. vaginalis, C. trachomatis, N. gonorrhoeae) in this study population were more likely associated with preterm births only. We believe point-of-care diagnostics and comprehensive management of these STIs in pregnancy could avert adverse pregnancy outcomes commonly associated with these STIs.

\section{Key messages}

- Genital shedding of herpes simplex virus-2 (HSV-2) is common among young HIV-1 infected women during pregnancy.

- Genital shedding of HSV-2 like the other common STIs Trichomonas vaginalis, Chlamydia trachomatis and Neisseria gonorrhoeae was largely asymptomatic during pregnancy.

- While symptomatic women are more likely to be treated the same day, close to one-third of women who are asymptomatic will not return for treatment.

- The occurrence of stillbirths (17.5\%) and low birth weight $(14.3 \%)$ were not significantly associated with HSV-2 shedding, HIV-1, C. trachomatis, N. gonorrhoeae and T. vaginalis.

- Asymptomatic women with untreated curable STIs were 3.3 times more likely to deliver prematurely when compared with women who received treatment during pregnancy.

- Reliable affordable point-of-care testing of STIs is urgently needed at public health facilities to ensure that all women with curable STIs receive treatment early in pregnancy.

\section{Handling editor Jackie A Cassell}

Contributors DM conceptualised the substudy, interpreted the statistical analysis and wrote the manuscript. BS performed the statistical analysis and contributed to the development of the manuscript. SM and VC coordinated the laboratory tests, interpreted the data and reviewed the manuscript. Susanne Maman was the principal investigator of the primary study, conceptualised the substudy and helped write the manuscript.

Funding This work was supported by the Eunice Kennedy Shriver National Institute of Child Health and Human Development (grant number R01HD050134) and The Open Society Institute and Elton John Foundation (grant number 20020472/ 20030878)

\section{Competing interests None declared.}

Ethics approval The main study was approved by the institutional review boards of the University of KwaZulu-Natal (E129/06) and the University of North Carolina at Chapel Hill (07-1070) and the University of KwaZulu-Natal ethics committee.

Provenance and peer review Not commissioned; externally peer reviewed.

\section{REFERENCES}

1 UNAIDS. Global report: UNAIDS report on the global AIDS epidemic 2013. 2013 http://www.unaids.org/en/media/unaids/contentassets/documents/epidemiology/ 2013/gr2013/UNAIDS_Global_Report_2013_en.pdf (accessed 22 May 2016).

2 Naidoo S, Wand H, Abbai NS, et al. High prevalence and incidence of sexually transmitted infections among women living in Kwazulu-Natal, South Africa. AIDS Res Ther 2014;11:31.

3 Jonas $\mathrm{K}$, Crutzen $\mathrm{R}$, van den Borne $\mathrm{B}$, et al. Teenage pregnancy rates and associations with other health risk behaviours: a three-wave cross-sectional study among South African school-going adolescents. Reprod Health 2016;13:50.

4 Althabe F, Moore JL, Gibbons L, et al. Adverse maternal and perinatal outcomes in adolescent pregnancies: the Global Network's Maternal Newborn Health Registry study. Reprod Health 2015;12(Suppl 2):S8.

5 Moodley D, Moodley P, Sebitloane M, et al. High prevalence and incidence of asymptomatic sexually transmitted infections during pregnancy and postdelivery in KwaZulu Natal, South Africa. Sex Trans Dis 2015;42:43-7.

6 Badman SG, Vallely LM, Toliman P, et al. A novel point-of-care testing strategy for sexually transmitted infections among pregnant women in high-burden settings: results of a feasibility study in Papua New Guinea. BMC Infect Dis 2016;16:250

7 Hokororo A, Kihunrwa A, Hoekstra P, et al. High prevalence of sexually transmitted infections in pregnant adolescent girls in Tanzania: a multi-community cross-sectional study. Sex Transm Infect 2015;91:473-8.

8 South African Department of Health. The 2012 National Antenatal Sentinel HIV and Herpes Simplex type-2 prevalence survey. South Africa: National Department of Health, 2013.

9 Moodley T, Moodley D, Sebitloane M, et al. Improved pregnancy outcomes with increasing antiretroviral coverage in South Africa. BMC Pregnancy Childbirth 2016;16:35.

10 Adachi K, Klausner JD, Xu J, et al., NICHD HPTN 040 Study Team. Chlamydia trachomatis and Neisseria gonorrhoeae in HIV-infected pregnant women and adverse infant outcomes. Pediatr Infect Dis / 35:894-900.

11 Ahmadi A, Khodabandehloo M, Ramazanzadeh R, et al. The relationship between Chlamydia trachomatis genital infection and spontaneous abortion. J Reprod Infertil 2016;17:110-16.

12 Blas MM, Canchihuaman FA, Alva IE, et al. Pregnancy outcomes in women infected with Chlamydia trachomatis: a population-based cohort study in Washington State. Sex Trans Infect 2007;83:314-18.

13 Adachi K, Nielsen-Saines K, Klausner JD. Chlamydia trachomatis infection in pregnancy: the Global Challenge of Preventing Adverse Pregnancy and Infant Outcomes in Sub-Saharan Africa and Asia. Biomed Res Int 2016;2016:9315757.

14 Li DK, Raebel MA, Cheetham TC, et al. Genital herpes and its treatment in relation to preterm delivery. Am J Epidemiol 2014;180:1109-17.

15 Bujko M, Sulovic V, Zivanovic $V$, et al. Herpes simplex virus infection in women with previous spontaneous abortion. J Perinat Med 1988;16:193-6.

16 Perti T, Nyati M, Gray G, et al. Frequent genital HSV-2 shedding among women during labor in Soweto, South Africa. Infect Dis Obstet Gynecol 2014;2014:258291.

17 Patterson J, Hitti J, Selke S, et al. Genital HSV detection among HIV-1-infected pregnant women in labor. Infect Dis Obstet Gynecol 2011;2011:157680.

18 Maman S, Moodley D, McNaughton-Reyes HL, et al. Efficacy of enhanced HIV counseling for risk reduction during pregnancy and in the postpartum period: a randomized controlled trial. PLOS ONE 2014;9:e97092.

19 Hollier LM, Wendel GD. Third trimester antiviral prophylaxis for preventing maternal genital herpes simplex virus (HSV) recurrences and neonatal infection. Cochrane Database Syst Rev 2008;(1):CD004946.

20 Wedi $\mathrm{CO}$, Kirtley S, Hopewell S, et al. Perinatal outcomes associated with maternal HIV infection: a systematic review and meta-analysis. Lancet HIV 2016;3:e33-48.

21 Folger AT. Maternal Chlamydia trachomatis infections and preterm birth: the impact of early detection and eradication during pregnancy. Matern Child Health J 2014; 18:1795-802.

22 Rastogi S, Das B, Salhan S, et al. Effect of treatment for Chlamydia trachomatis during pregnancy. Int I Gynaecol Obstet 2003;80:129-37.

23 Gray RH, Wabwire-Mangen F, Kigozi G, et al. Randomized trial of presumptive sexually transmitted disease therapy during pregnancy in Rakai, Uganda. Am J Obstet Gynecol 2001;185:1209-17.

24 Hill MG, Menon S, Smith S, et al. Screening for Chlamydia and Gonorrhea Cervicitis and implications for pregnancy outcome. Are we testing and treating at the right time? J Reprod Med 2015;60:301-8.

25 Wynn A, Ramogola-Masire D, Gaolebale P, et al. Acceptability and feasibility of sexually transmitted infection testing and treatment among pregnant women in Gaborone, Botswana, 2015. Biomed Res Int 2016;2016:1251238

26 Brook G. The performance of non-NAAT point-of-care (POC) tests and rapid NAAT tests for chlamydia and gonorrhoea infections. An assessment of currently available assays. Sex Transm Infect 2015;91:539-44.

27 Kinuthia J, Drake AL, Matemo D, et al. HIV acquisition during pregnancy and postpartum is associated with genital infections and partnership characteristics. AIDS 2015;29:2025-33. 